\title{
Effects of Material Properties on Switched Reluctance Motor Vibration Determination
}

\author{
Zhangjun Tang \\ Stryker Instruments \\ Kalamazoo, MI 49001 \\ Phone: 269-323-7700 Ext.3603 \\ Fax: 269-323-3094 \\ ztang@inst.strykercorp.com
}

\author{
Pragasen Pillay \\ ECE Department \\ Clarkson University \\ Potsdam, NY 13699 \\ Phone: 315-268-6509 \\ Fax: 315-268-7600 \\ pillayp@clarkson.edu
}

\author{
Avoki M. Omekanda \\ Delphi Research Labs \\ 51786 Shelby Parkway \\ Shelby Township, MI 48306 \\ Phone: (586) 323-6161 \\ Fax: (596) 323-9898 \\ avoki.omekanda@delphi.com
}

\author{
Chen Li, Cetin Cetinkaya \\ Mechanical Engineering \\ Department \\ Clarkson University \\ Potsdam, NY 13699
}

\begin{abstract}
The switched reluctance motor is well known for its higher acoustic noise, caused by stator vibrations. Techniques for noise reduction require knowledge of the modal frequencies, which depend on mechanical shapes and dimensions as well as material properties, for example, Young's modulus, Poisson's ratio, mass density, etc. It is found that the generally accepted value of Young's modulus is not valid for a machine with laminations and no frame. This paper introduces a simple and nondestructive method for the measurement of Young's modulus; it is then used in a finite element program to determine the resonant frequencies of SRM stator vibration. The effects of mass density and Poisson's ratios are also discussed. The FE results are validated by vibration tests, which show good accuracy.
\end{abstract}

\section{Introduction}

Vibration and acoustic noise in the switched reluctance motor is caused by the ovalizing deformation of the stator lamination stack due to its radial magnetic attraction to the rotor [1]. This is a big disadvantage for industrial applications. There are several ways of determining stator resonant frequencies and mode shapes of the SRM: analytical calculations, numerical computation (usually by the finite element method), and/or experimental measurements [2]. There is considerable advantage and interest in using numerical methods for the computation of resonant frequencies and mode shapes during motor design. The material properties, like mass density and Young's modulus are key factors besides stator dimensions and shapes. In the approximate formula for stator natural frequency, the stator resonant frequency has the relation [3]

$$
f_{r} \propto \sqrt{\frac{E}{\rho}}
$$

Where $f_{r}$ is the stator natural frequency, $E$ and $\rho$ are the Young's modulus and mass density of the stator material respectively.

The density of the lamination core can be easily determined, however Young's modulus deserves some consideration. The Young's modulus value of stainless steel $\left(\mathrm{E}=2.07 \times 10^{11} \mathrm{~N} / \mathrm{m}^{2}\right)$ has been widely used by researchers in electric machine vibrations area. However in order to allow theoretical prediction to converge to experimental results, some researchers even varied the value until the predicted natural frequencies converged to the measured values [4]. The fact is that the stator lamination steel of an electric machine is different from stainless steel, in addition, the material properties may change during core lamination or motor manufacturing. Because of the important role it plays in the determination of stator natural frequencies and its complexity, the treatment of Young's modulus has to be considered seriously.

\section{Young's Modulus Measurement}

\subsection{Methodology}

Many useful mechanical properties of materials, like Young's modulus, are obtained from tension tests and/or compression tests [5]. However these tests are not trivial for an electric machine stator. Firstly, the force load may change the electromagnetic properties of the stator laminations. Secondly, the test may damage the stator lamination and/or windings. Finally the odd shape of an electric machine stator makes it difficult for mounting.

The other method widely used by mechanical and material researchers is an ultrasonic method, which is nondestructive. This is especially good for an electric machine. It will be discussed in detail in this paper.

The ultrasonic technique is a method for measuring the elastic properties of a material. The sample to be measured is placed between an ultrasonic transmitter (pulser) and receiver, and the time for an ultrasonic pulse to traverse the media between the transducers is measured. The block diagram is shown in Fig.1.

Stress waves from $20 \mathrm{~Hz}$ to $20 \mathrm{kHz}$ are perceived as sound. Waves above $20 \mathrm{kHZ}$ are referred to as ultrasonic; ultrasonic frequencies between $1 \mathrm{MHz}$ and $10 \mathrm{MHz}$ are commonly used in the nondestructive evaluation of engineering materials, for materials characterization. 


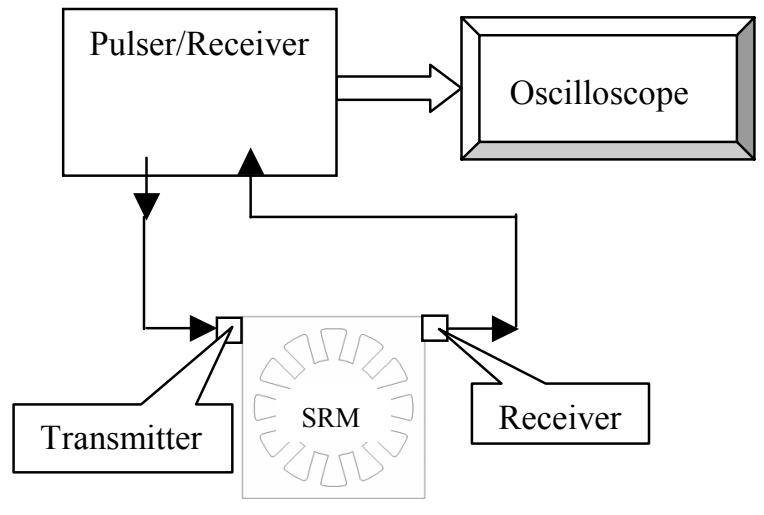

Fig.1 Block diagram of Ultrasonic method

Ultrasonic wave speed, c, depends on the stiffness and on the density, $\rho$, of the materials under study $[6,7]$. For longitudinal waves

$c=\sqrt{\frac{E}{\rho}}$

Where $\mathrm{E}$ is the Young's modulus. This is valid for a long homogeneous rod of length much longer than the wavelength, and width much less than the wavelength. If the width is much larger than the wavelength, then wave speed is governed by the tensorial modulus

$$
c=\sqrt{\frac{1-v}{(1+v)(1-2 v)} \frac{E}{\rho}}
$$

Where $v$ is the Poisson's ratio. The test motor stator used in this paper belongs to this category. So the Young's modulus of the motor stator can be described as:

$E=\frac{(1+v)(1-2 v)}{(1-v)} \rho c^{2}$

Velocity (wave speed c) can be measured by determining the time delay for the wave to pass through a sample of material. The velocity is the distance (thickness) divided by the time delay. In this method, one transducer sends the waves and another one receives them.

\subsection{Test Setup}

The prototype SRM used in this paper is shown in Fig.2 (the stator part with windings). Fig.3 shows the abovedescribed ultrasonic method that is used to measure Young's modulus of this 12/8 3-phase SRM stator core lamination. A 200MHz Computer Controlled Pulser/Receiver together with two transducers (KB-Aerotech, GAMA $2.25 \mathrm{MHz} / .50$ ) are used. The test data is then recorded in a digital oscilloscope and analyzed in a computer program to obtain the wave speed and Young's modulus.

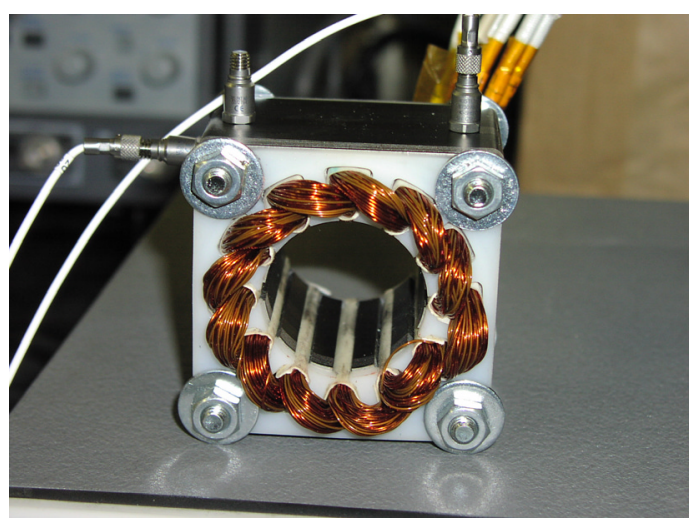

Fig.2 Stator of the Prototype SRM

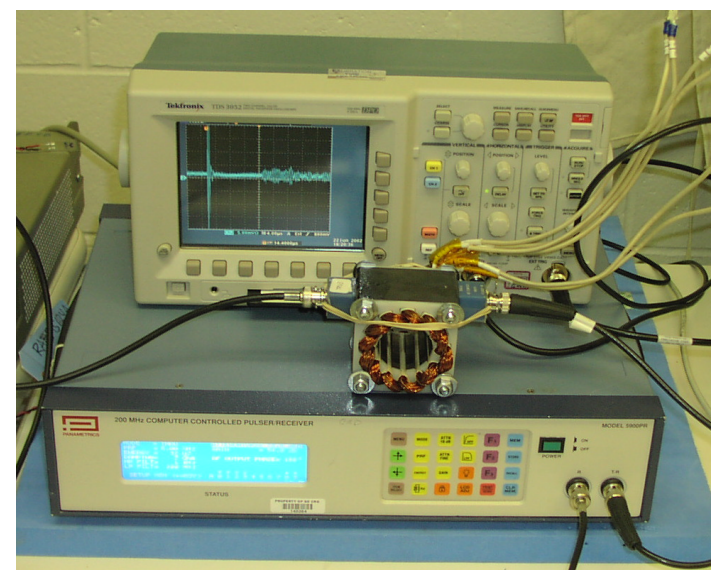

Fig.3 Test setup

Comparing with the traditional tension /compression method, the ultrasonic method has several advantages. Firstly, it is fast, convenient and simple and no special hydraulic equipment is needed. Secondly, no special mounting is needed, the transducers are attached to the test object where needed. Then no damage is done to the stator or to the windings. Finally it is easy to change the test location, for example, in horizontal direction or vertical direction, or from the inner side of stator pole.

\subsection{Test Results}

Fig.4 records the travel time of the ultrasonic signal inside the stator core lamination. The wave speed $\mathrm{c}$ can then be calculated, knowing the length of the test object (SRM stator). Using equation (4), Young's modulus $\mathrm{E}$ of the stator lamination is obtained in both the vertical and lateral directions (as viewed in Fig.2). Where, Poisson's ratio $v=$ $0.3[4,5,6]$, mass density $\rho=0.935 \times 7.8 \times 10^{3} \mathrm{~kg} / \mathrm{m}^{3}, 0.935$ is the stacking factor (generally it is $0.92 \sim 0.95$ ) of the stator core lamination. The measured value is $1.521 \times 10^{11} \mathrm{~N} / \mathrm{m}^{2}$, and is the same in both directions, quite different from $2.07 \times$ $10^{11} \mathrm{~N} / \mathrm{m}^{2}$ used by most researchers. 
Some other Poisson's ratio values are also used to calculate the Young's modulus, which are listed in Table 1. They will also be used later in FE program for determination of resonant frequency for comparison purpose.

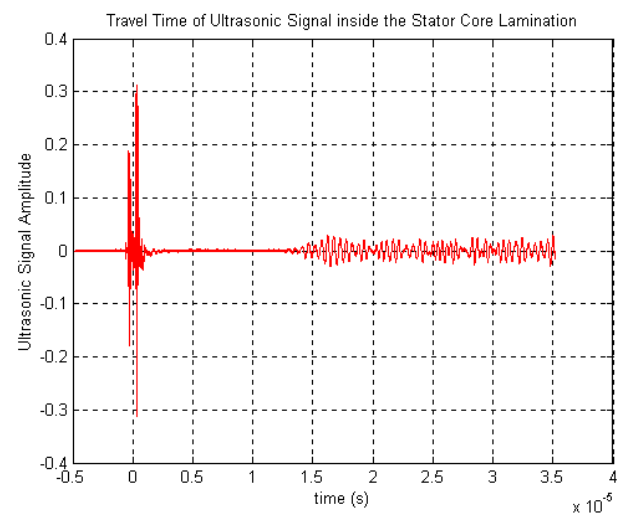

(a) Vertical Direction

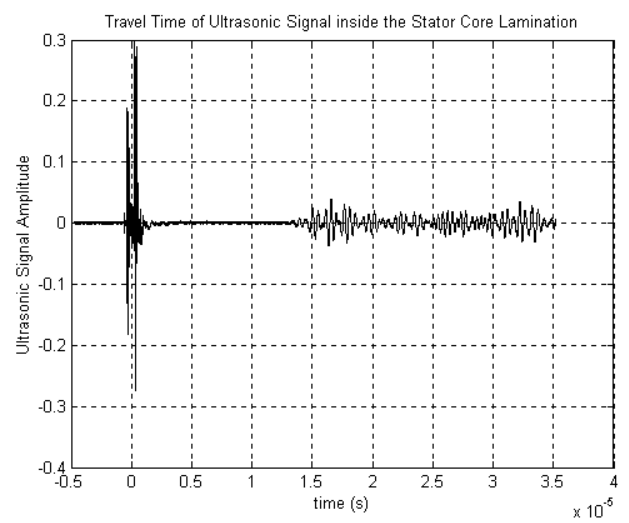

(b) Lateral Direction

Fig.4 Travel Time of Ultrasonic Signal inside the Stator Core Lamination

Table 1 Measured Young's Modulus

\begin{tabular}{|c|c|}
\hline Poisson's Ratio v & Young's Modulus E $\left(\times 10^{11} \mathrm{~N} / \mathrm{m}^{2}\right)$ \\
\hline 0.3 (Commonly Used) & 1.521 \\
\hline 0.27 & 1.638 \\
\hline 0.34 & 1.371 \\
\hline 0 (One-dimensional) & 2.047 \\
\hline
\end{tabular}

\section{Calculation Results}

\subsection{Equivalent Mass Density Determination}

The effect of phase windings on the vibration of electric machines has been discussed by many studies $[9,10,11]$. Generally it is believed that the windings have effects of both additional mass and vibration damping on the vibrational behavior of electric machines. In this paper, the mass of phase windings is treated as increase of the mass density of the pole to which the winding is attached. According to [11], the concentrated windings of the SRM are installed on the stator poles. There is insulation between a pole and winding. For conventional motors, the contact between pole and winding assembly is tight enough to allow the windings to move with the pole, but cannot add an extra stiffness due to the existence of the insulation. Although the windings may contribute to stiffness if the slot fill factor is high, the increase in the stiffness is low when compared to the mass added by the windings to the stator assembly. Therefore, the effect of windings is equated to an increase of the pole mass. As a result, the geometrical model for finite element computation is the same as the model without considering the winding effect, but the poles are treated as a different material with specific mass density. The equivalent mass density of the pole with winding effect will be explained explicitly as follows.

The equivalent mass density $\rho$ e can be expressed as $\rho_{e}=\frac{m_{\text {pole }}+m_{\text {coil }}}{V_{\text {pole }}}$, where $\mathrm{m}_{\text {pole }}$ is the mass of one pole, $\mathrm{m}_{\text {coil }}$ is the mass of the coil attached to one pole, $\mathrm{V}_{\text {pole }}$ is the volume of the pole.

The volume of the pole $V_{\text {pole }}=L_{\text {stack }} \times H_{\text {pole }} \times W_{\text {pole }}$, where $\mathrm{L}_{\text {stack }}$ is the length of the pole (which is the same as stator stack length), $\mathrm{H}_{\text {pole }}$ is the height if the pole and $\mathrm{W}_{\text {pole }}$ is the width of the pole.

The mass of one pole is $m_{\text {pole }}=\rho_{F e} \times f_{\text {stack }} \times V_{\text {pole }}$, where $\rho_{\mathrm{Fe}}$ is the mass density of steel, $\mathrm{f}_{\text {stack }}$ is stacking factor of the stator lamination, generally it is $0.92 \sim 0.95$.

The mass of the coil can be calculated as $m_{\text {coil }}=N_{\text {turn }} \times m_{\text {turn }}$, where $\mathrm{N}_{\text {turn }}$ is the turns of winding per pole and $\mathrm{m}_{\text {turn }}$ is the mass of each turn. The mass of each turn of the coil $m_{\text {turn }}=\rho_{c u} \times L_{\text {turn }} \times A_{\text {turn }}$, where $\rho_{\text {cu }}$ is the mass density of copper, $L_{\text {turn }}$ is the length of each turn and $A_{\text {turn }}$ is the intersection area of copper wire. Fig. 4 shows the shape of one turn of the coil, from which the length of each turn can be calculated, $L_{\text {turn }}=2 \pi R_{\text {oh }}+2 L_{\text {copper }}$, where $\mathrm{R}_{\mathrm{oh}}$ is the radius of the winding overhang, $\mathrm{L}_{\text {copper }}$ is the length of the straight line shown in Fig.5, which is longer than the stator stack length. The intersection area of copper wire can be calculated as $A_{\text {turn }}=\pi\left(\frac{D_{\text {barewire }}}{2}\right)^{2}$, where $\mathrm{D}_{\text {barewire }}$ is the diameter of the bare copper wire with corresponding A.W.G.

Finally, the equation for equivalent mass density of the pole is: 
$\rho_{e}=\frac{\rho_{F e} \times f_{\text {stack }} \times\left(L_{\text {stack }} \times H_{\text {pole }} \times W_{\text {pole }}\right)+N_{\text {turn }} \times\left\{\rho_{\text {cu }} \times\left(2 \pi R_{\text {oh }}+2 L_{\text {stack }}\right) \times\left[\pi\left(\frac{D_{\text {barewire }}}{2}\right)^{2}\right]\right\}}{\left(L_{\text {stack }} \times H_{\text {pole }} \times W_{\text {pole }}\right)}$

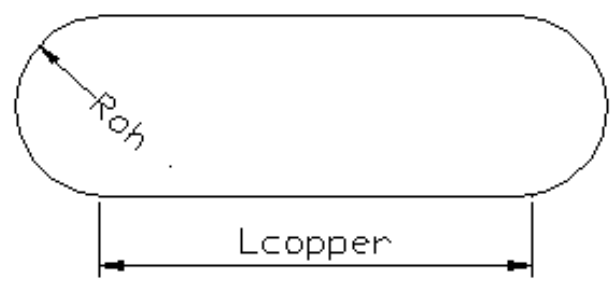

Fig.5 One Turn of the Coil

The equivalent density of the pole is $20.29 \times 10^{3} \mathrm{~kg} / \mathrm{m}^{3}$.

\subsection{Finite Element Analysis}

A 3-D FE model is constructed for this motor, as shown in Fig.6. The measured Young's modulus E is used with the ANSYS 3-D model to determine the natural frequencies, with the $2^{\text {nd }}$ modes being at $1563.8 \mathrm{~Hz}$ and $2578.1 \mathrm{~Hz}$.
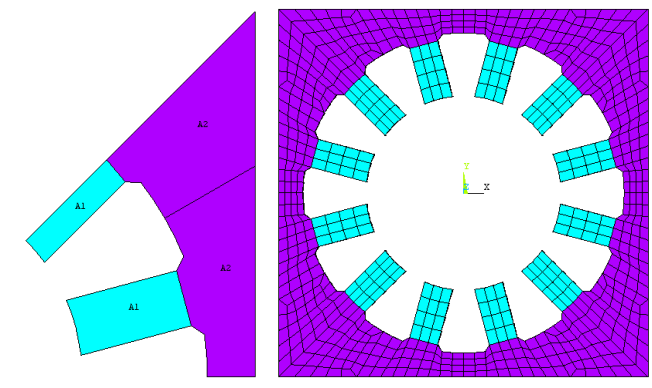

(a) Basic Area

(b) Basic Elements
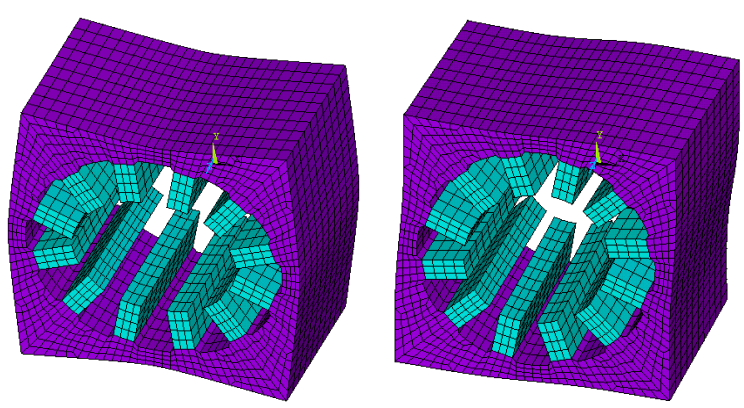

(c) $2^{\text {nd }}$ Mode Shape at $1563.8 \mathrm{~Hz}$

(d) $2^{\text {nd }}$ Mode Shape at $2578.1 \mathrm{~Hz}$

Fig.6 FE Basic Area, Mesh and $2^{\text {nd }}$ Mode Shapes (with measured Young's modulus)

The commonly used Young's modulus $\left(2.07 \times 10^{11} \mathrm{~N} / \mathrm{m}^{2}\right)$ is also used in the FE program to re-evaluate the resonant frequencies. Both are given in Table 2. To evaluate the effect of Poisson's ratio on the resonant frequencies, a different Poisson's ratio value, $v=0.34$ and $0.27[6,12]$, is used in the FE program, with all the other material properties kept the same. No effect has been observed by changing this value.

\section{Experimental Validation}

In order to validate the $\mathrm{FE}$ calculations of resonant frequencies, a force hammer test is carried out for the SRM. Fig.7 shows the time domain hammer impulse force, damped transient stator acceleration and frequency domain acceleration. It can be seen clearly that the $2^{\text {nd }}$ mode resonant frequencies, which are $1497 \mathrm{~Hz}$ and $2655 \mathrm{~Hz}$ respectively, are very close to the calculated ones with the measured Young's modulus (the peak of $2095 \mathrm{~Hz}$ appeared in this figure is the resonant frequency of the test setup). The errors between the calculated and measured resonant frequencies are less than $4.5 \%$ for both resonant frequencies, as shown in Table 2, row 1). The errors of the calculated resonant frequencies using commonly used Young's modulus are $21.9 \%$ and $13.3 \%$ respectively, as listed in Table 2, row 2).
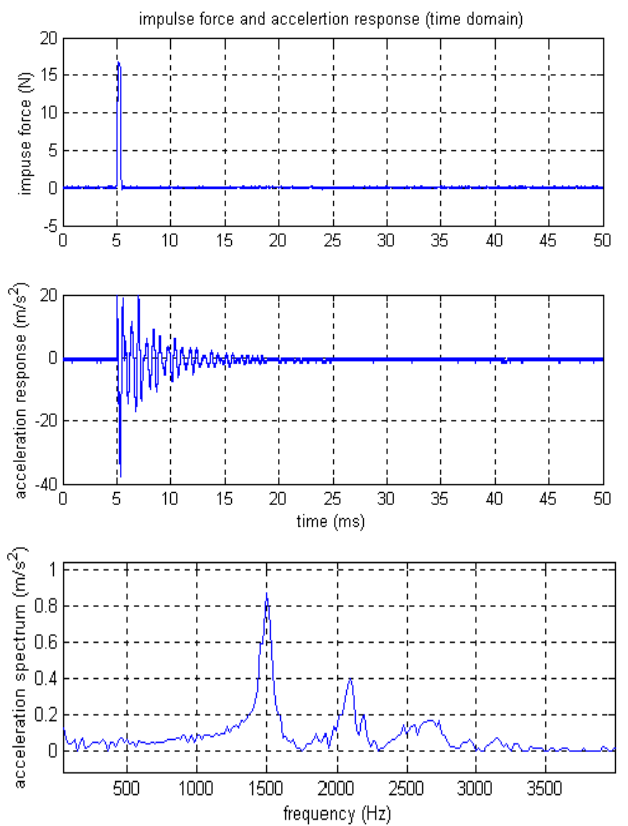

Fig.7 Force Hammer Test Result: Force Impulse and Stator Acceleration

\section{Comparisons}

The effects of Young's modulus, equivalent mass, Poisson's ratio and stator core lamination stacking factor on the resonant frequencies are studied. These results are compared with impulse hammer test results, as shown in Table 2 . 
Row 1) shows the calculated resonant frequencies with measured Young's modulus, commonly used Poisson's ratio, consideration of winding effect and stacking factor. Both errors are less than $4.5 \%$ compared with the impulse force hammer tests.

Row 2) shows the calculated results with commonly used Young's modulus $\left(2.07 \times 10^{11} \mathrm{~N} / \mathrm{m}^{2}\right)$, the calculation error are not acceptable although the winding effect and stacking factor are considered, with $21.9 \%$ and $13.3 \%$ respectively.

Row 3), 4), 5) show the effect of Poisson's ratio on the resonant frequencies, no major effect has been found. The
Poisson's ratio $v=0$ here refers to the so-called "onedimensional" material.

Row 6), 7), 8) show the role of Poisson's ratio on the accurate determination of Young's modulus during ultrasonic measurements, which is based on equation (4). Comparing with row 1), the commonly used Poisson's ratio $v=0.3$ has the best result, while $v=0.27$ and 0.34 have acceptable results, both errors are around $8 \% . \quad v=0$, which refers to homogeneous one-dimensional structure, leads to $20 \%$ error. The Young's modulus determination of electric machine stators can't be treated as homogeneous structure.

Table 2 Effect of Young's Modulus on the Resonant Frequencies of the 2nd Mode Shapes

\begin{tabular}{|l|c|c|c|c|c|c|c|c|}
\hline & $\mathrm{E}$ & $\rho_{1}$ & $\rho_{2}$ & $v$ & $\mathrm{f}_{2}$ & $\mathrm{f}_{2}$ (error \%) & $\mathrm{f}_{2}{ }^{\prime}$ & $\mathrm{f}_{2}{ }^{\prime}$ (error \%) \\
\hline 1$)$ & $\mathbf{1 . 5 2 1}$ & $\mathbf{2 0 . 2 9}$ & $\mathbf{7 . 8 \times 0 . 9 3 5}$ & $\mathbf{0 . 3}$ & $\mathbf{1 5 6 3 . 8}$ & $\mathbf{4 . 5}$ & $\mathbf{2 5 7 8 . 1}$ & $\mathbf{- 2 . 9}$ \\
\hline \hline 2$)$ & 2.07 & 20.29 & $7.8 \times 0.935$ & 0.3 & 1824.3 & 21.9 & 3007.7 & 13.3 \\
\hline \hline 3$)$ & 1.521 & 20.29 & $7.8 \times 0.935$ & 0.27 & 1562.9 & 4.4 & 2577.4 & -2.9 \\
\hline 4$)$ & 1.521 & 20.29 & $7.8 \times 0.935$ & 0.34 & 1565.1 & 4.6 & 2579.2 & -2.9 \\
\hline 5$)$ & 1.521 & 20.29 & $7.8 \times 0.935$ & 0 & 1558.6 & 4.1 & 2573.2 & -3.1 \\
\hline 6$)$ & 1.638 & 20.29 & $7.8 \times 0.935$ & 0.27 & 1621.9 & 8.3 & 2674.7 & 0.7 \\
\hline 7$)$ & 1.371 & 20.29 & $7.8 \times 0.935$ & 0.34 & 1485.9 & -0.7 & 2448.7 & -7.8 \\
\hline 8$)$ & 2.047 & 20.29 & $7.8 \times 0.935$ & 0 & 1808.1 & 20.8 & 2985.7 & 12.5 \\
\hline 9$)$ & 1.627 & 20.80 & 7.8 & 0.3 & 1586.4 & 6.0 & 2608.6 & -1.7 \\
\hline 10$)$ & 2.07 & 7.8 & 7.8 & 0.3 & 2344.9 & 56.6 & 3621.3 & 36.4 \\
\hline 11$)$ & 2.07 & $7.8 \times 0.935$ & $7.8 \times 0.935$ & 0.3 & 2425.1 & 62.0 & 3745.0 & 41.1 \\
\hline 12$)$ & 1.521 & $7.8 \times 0.935$ & $7.8 \times 0.935$ & 0.3 & 2078.8 & 38.9 & 3210.2 & 20.9 \\
\hline 13$)$ & 1.521 & 28.59 & $7.8 \times 0.935$ & 0.3 & 1383.5 & -7.6 & 2326.7 & -12.4 \\
\hline
\end{tabular}

Note: The measured $2^{\text {nd }}$ resonant frequencies are $1497 \mathrm{~Hz}$ and $2655 \mathrm{~Hz}$ respectively (see also the next section), which are used as basis for calculating the percentage errors.

$\mathrm{E}=$ Young's modulus $\left(\times 10^{11} \mathrm{~N} / \mathrm{m}^{2}\right)$

$\rho_{1}=$ mass density of stator pole $\left(\times 10^{3} \mathrm{~kg} / \mathrm{m}^{3}\right)$

$\rho_{2}=$ mass density of stator core lamination $\left(\times 10^{3} \mathrm{~kg} / \mathrm{m}^{3}\right)$

$\mathrm{v}=$ Poisson's ratio

$\mathrm{f}_{2}, \mathrm{f}_{2}{ }^{\prime}=2^{\text {nd }}$ mode resonant frequencies

0.935 is the stator core lamination stacking factor (generally it is $0.92 \sim 0.95$ )

Rows 9) reveals the effect of stator core lamination stacking factor on the resonant frequency. The properties of stacked lamination are definitely different from that of iron or steel, as can be seen from the Young's modulus measurements. The existence of stacking factor will change the mass of the object, hence the resonant frequencies.

Rows 10) and 11) are the calculated results with commonly used Young's modulus without considering winding effects [13]. This is a commonly used method during the electric machine design stage because of the lack of winding parameters. The results reveal the fact that winding effects cannot be neglected, otherwise unacceptable errors will occur. In row 10) errors of $56.6 \%$ and $36.4 \%$ occur when neglecting the stacking factor, and in row11) errors are $62.0 \%$ and $41.1 \%$ when considering the stacking factor. The calculation results are still unacceptable if winding effects are not considered, even though a correct Young's Modulus is used, as seen in row 12), where errors are $38.9 \%$ and $20.9 \%$ for the two $2^{\text {nd }}$ mode frequencies.

Row 13) describes an easily made mistake when determining the equivalent mass density of the stator pole using the total wire diameter instead of the bare wire diameter (notice that there is an insulation layer for winding copper wires), hence increasing the equivalent mass and lowering the resonant frequencies. 


\section{Study on a $2^{\text {nd }}$ SRM}

A $4 \mathrm{~kW} 8 / 6 \mathrm{SRM}$ is used as a $2^{\text {nd }}$ motor in this paper to study the effects of material properties. Fig. 8 shows the 3-D FE model and a $2^{\text {nd }}$ mode modal shape (end-bells and rotor are not included). Different materials properties are used in the FE model to calculate the $2^{\text {nd }}$ mode resonant frequency, and then compare to the measured one. The measured $2^{\text {nd }}$ mode resonant frequency is $1060.4 \mathrm{~Hz}$. This is used as a base for calculation error percentage. Table 3 shows FE calculation results with different material properties.
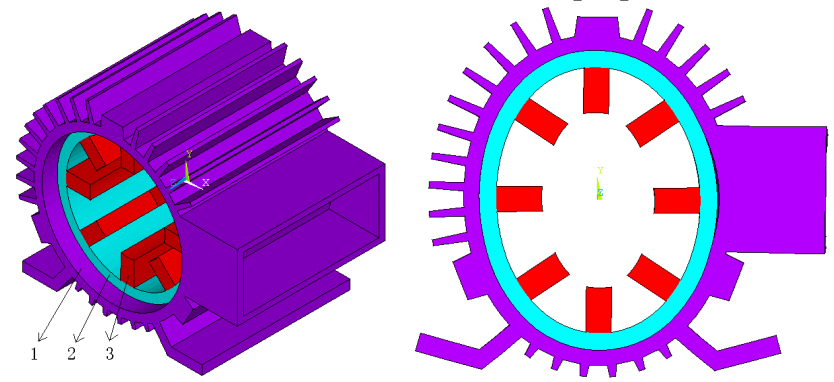

(1-casting iron frame; 2 -lamination, 3-equivalent material with winding effect considered)

Fig.8 3-D FE Model and $2^{\text {nd }}$ Mode Shape

As compared in Table 3, Case 3 (measured Young's Modulus $1.521 \times 10^{11} \mathrm{~N} / \mathrm{m}^{2}$ used, with winding effect, with stacking factor considered) doesn't change the resonant frequency as much as that in the 12/8 SRM described above. This means that the Young's modulus is less important for the determination of resonant frequencies in the SRM with a cast iron frame. Case 4 shows again that winding effect has to be considered.

Table 3 Effect of material properties on Oulton SRM

\begin{tabular}{|c|c|c|c|c|}
\cline { 2 - 5 } \multicolumn{1}{c|}{} & Case 1 & Case 2 & Case 3 & Case 4 \\
\hline $\mathrm{f}_{2}(\mathrm{~Hz})$ & 1040.6 & 1054.9 & 1027.9 & 1369.7 \\
\hline $\mathrm{f}_{2}($ Error $\%)$ & -1.9 & -0.5 & -3.1 & 29.2 \\
\hline \hline $\mathrm{E}_{1}\left(\times 10^{11} \mathrm{~N} / \mathrm{m}^{2}\right)$ & 1.6 & 1.6 & 1.6 & 1.6 \\
\hline$v_{1}$ & 0.275 & 0.275 & 0.275 & 0.275 \\
\hline$\rho_{1}\left(\times 10^{3} \mathrm{~kg} / \mathrm{m}^{3}\right)$ & 7.8 & 7.8 & 7.8 & 7.8 \\
\hline \hline $\mathrm{E}_{2}\left(\times 10^{11} \mathrm{~N} / \mathrm{m}^{2}\right)$ & 2.07 & 2.07 & 1.521 & 2.07 \\
\hline$v_{2}$ & 0.3 & 0.3 & 0.3 & 0.3 \\
\hline$\rho_{2}\left(\times 10^{3} \mathrm{~kg} / \mathrm{m}^{3}\right)$ & 18.59 & 18.083 & 18.083 & 7.293 \\
\hline \hline $\mathrm{E}_{3}\left(\times 10^{11} \mathrm{~N} / \mathrm{m}^{2}\right)$ & 2.07 & 2.07 & 1.521 & 2.07 \\
\hline$v_{3}$ & 0.3 & 0.3 & 0.3 & 0.3 \\
\hline$\rho_{3}\left(\times 10^{3} \mathrm{~kg} / \mathrm{m}^{3}\right)$ & 7.8 & 7.293 & 7.293 & 7.293 \\
\hline
\end{tabular}

Note:

Case 1 - Commonly used material properties, with winding effect;

Case 2 - Commonly used material properties, with winding effect, with stacking factor considered;

Case 3 - Measured Young's Modulus used, with winding effect, with stacking factor considered;

Case 2 - Commonly used material properties, without winding effect, with stacking factor considered.

\section{Conclusions}

A convenient and nondestructive method for the measurement of Young's modulus of stacked lamination in electric motor stators is introduced in this paper. It shows the importance of Young's modulus in the calculation of stator resonant frequencies. The commonly used Young's modulus value is not appropriate for the calculation of resonant frequencies in the motor without a frame, however it produces lower errors for the motor with frame. The results are validated by a 3-D FE calculation together with force hammer vibration tests.

The Poisson's ratio is important for determining the Young's modulus using ultrasonic tests. It is necessary to include the stator core lamination stacking factor, the winding effects, together with appropriate Young's modulus value for resonant frequencies determination during the design phase of SRMs.

\section{References:}

[1] D.E. Cameron, J.H. Lang, S.D.Umans, "The origin and reduction of acoustic noise in doubly salient variablereluctance motors", IEEE Trans. on Industry Applications, vol.28, n6, November/December, 1992, pp.1250-1255.

[2] Praveen Vijayraghavan, R. Krishnan, "Noise in electric machines: A review", IEEE Trans. on Industry Applications, vol.35, n5, Sep.1999, pp.1007-1013.

[3] R.S.Colby, F.Mottier, T.J.E.Miller, "Vibration modes and acoustic noise in a 4-phase switched reluctance motor", IEEE Trans. on Industry Applications, vol.32, n6, pp.13571364, November / December 1996.

[4] Long, S.A., Zhu, Z.Q.; Howe, D.; "Vibration behavior of stators of switched reluctance motors", IEE Proceedings: Electric Power Applications, vol.148, n3, May 2001, pp.257264.

[5] Roy R. Craig, JR., "Mechanics of Materials", ISBN 0471-50284-7, John Wiley \& Sons, 1996.

[6] W. Michael Lai, David Rubin, Erhard Krempl, "Introduction to Continuum Mechanics", ISBN 0-75062894-4, Butterworth-Heinemann, 1993.

[7] Karl F. Graff, "Wave Motion in Elastic Solids", ISBN 0-486-66745-6, Dover Publications, 1975.

[8] C. Cetinkaya, "Localization of Longitudinal Waves in Bi-periodic Elastic Structures with Disorder", Journal of Sound and Vibration, 1999, 221(1), pp.49-66.

[9] S.P.Verma, R.S.Girgis, "Method for accurate determination resonant frequencies and vibration behavior of stators of electrical machines", Proceedings of IEE, Part B, Vol.128, No.1, January 1981, pp.1-11.

[10] C. Yongxiao, W. Jiahua, H. Jun, "Analytical Calculation of Natural Frequencies of Stator of Switched Reluctance Motor", IEE EMD97, Sept.1 3, 1997, pp.81 85.

[11] W.Cai, P.Pillay, Z.Tang, "Impact of Stator Windings and End Bells on Resonant Frequencies and Mode Shapes of Switched Reluctance Motors", IEEE Transactions on 
Industry Applications, Vol.38, No.4, July/August 2002, pp.1027 1036.

[12] Z.Q.Zhu, L.Xu, D.Howe, "Influence of Mounting and Coupling on the Natural Frequencies and Acoustic Noise Radiated by a PWM Controlled Induction Machine", IEE Conference Publication, n468, 1999, Proceedings of the 1999 9th International Conference on Electrical Machines and Drives (EMD99), Sep 1-Sep 3 1999, Canterbury, UK, pp.164 168.

[13] W.Cai, P.Pillay and A.Omekanda, "Low Vibration Design of SRMs for Automotive Applications Using Modal Analysis", IEEE IEMDC, Boston, MA, June 2001, pp.261 266.

[14] Jeff Mahn, Don Williams, Pete Wung, Gary Horst, Jerry Llooyd, Steve Randall, "A Systematic Approach Toward Studying Noise and Vibration in Switched Reluctance Machines: Preliminary Results", IEEE IAS 31st Annual Meeting, Oct.6 10, 1996, San Diego, pp.779 785. 